\title{
La Adquisición de Competencias en los Alumnos del Grado en Relaciones Laborales y Recursos Humanos de la Universidad de Huelva
}

\author{
Jerónimo Sepúlveda Reyes* \\ Ángel Boza Carreño***
}

RESUMEN:

La declaración de Bolonia plantea nuevos objetivos académicos para adecuarse a las necesidades que exige el mercado de trabajo, y ello implica la transformación de los sistemas educativos para adaptarse a los requerimientos de la nueva coyuntura de los sistemas productivos. Bolonia crea el Espacio Europeo de Educación Superior (EEES) y una de sus premisas se basa en la adquisición de competencias porparte del estudiante.

En esta investigación se pretende conocer la opinión de un grupo de alumnos de segundo curso del grado en Relaciones Laborales y Recursos Humanos de la Universidad de Huelva sobre la importancia y el grado de adquisición de varias competencias seleccionadas. Para ello se les facilitó un doble cuestionario en escala tipo Likert. El primero con la valoración de dichas competencias y el segundo con el grado de adquisición que creen poseer de cada una de ellas. Los resultados evidencian desajustes entre importancia y adquisición, asi como diferencias estadísticamente significativas en función de las situaciones personales de los alumnos.

Palabras Clanes:

Competencias genéricas y especificas; educación superior; aprendizaje; habilidades.

* Universidad de Huelva $\bullet$ jeronimo.sepulveda@dam.uhu.es

** Universidad de Huelva $\bullet$ aboza@uhu.es 


\section{ABSTRACT:}

The Bologna declaration has created new academic goals in order to suit the labor market demands, and this implies the transformation of education systems to adjust to the new situation in the production systems. Bologna sets up the European Higher Education Area (EHEA), and the acquisition of skills by the students as one of its fundamental principles.

This reseach aims to assess the views of a group of second-year students (degree in Labour Relations and Human Resources management - UNIVERSITY OF HUELVA) on the importance and the extent to which they think to have acquired severat selected competencies. They were provided with a double Liker type scale questionnaire. The first one had the assessment of thease skills and the second the extent to which they thought to have acquired in everyone of them.

The findings show disparities between their importance and acquisition, as well as statisally significant differences in correlation to the students personal situations.

KEYWORDS:

Generic and specifc competences; higher education; learning; skills.

\section{1.- INTRODUCCIÓN}

Las transformaciones sociales y económicas de los últimos tiempos, obligan a redefinir los perfiles profesionales que demanda el mercado de trabajo. La globalización, los cambios tecnológicos, las nuevas formas de organización del trabajo o las variaciones en la demanda de bienes y servicios, requieren modificaciones significativas de los recursos humanos en las empresas. De la producción en masa y de unas necesidades de mano de obra ajustadas por unos determinados conocimientos pasamos a un escenario caracterizado por la flexibilidad, que requiere no sólo unos conocimientos teóricos adaptados a la realidad empresarial, sino también unas competencias genéricas que propicien la acomodación de los trabajadores a las situaciones que exija un entorno tan cambiante. Por ello uno de los grandes retos de las universidades radica en adaptar la educación superior a las demandas del mercado y conseguir la empleabilidad de los titulados.

Ya el informe Delors (1996) presentaba la educación como una experiencia a lo largo de la vida de cada individuo basada en 4 pilares: aprender a conocer, a convivir, vivir juntos y aprender a hacer, concluyendo que conviene que el estudiante no se limite a aprender un oficio, sino también a adquirir unas competencias que le permita enfrentarse a situaciones diferentes e incluso a veces imprevisibles.

Para el desempeño de un puesto de trabajo no son suficientes los meros conocimientos y es necesario aprender a ponerlos en práctica, saber estar ó trabajar en 
equipo (desarrollar un conjunto de destrezas y habilidades y un conjunto de actitudes y valores destinados a tender puentes entre los sistemas educativos y los mercados de trabajo). Por ello, uno de los objetivos del proceso de convergencia europea es el de rediseñar los procedimientos de enseñanza aprendizaje para formar profesionales competentes. El reto es ajustar la formación superior a las necesidades que requiere la sociedad, conseguir estudiantes competentes capaces de insertarse con garantías en el mundo laboral. No es suficiente la mera transmisión de conocimientos, sino que hay que formar en competencias. Aparece este nuevo concepto que cobra gran importancia en los cambios que se están produciendo en los modelos educativos. Pero, ¿a qué responde realmente el término competencia?

Las competencias son una combinación de recursos propios (conocimientos, saber hacer, cualidades o aptitudes), encaminados a la aplicación en un entorno laboral (Le Bofert, 2001). Otros autores las entienden como un potencial de conductas adaptadas a una situación (De Miguel, 2006). En este sentido, posee competencia profesional quien dispone de los conocimientos, destrezas y actitudes necesarias para ejercer su propia actividad laboral, resuelve los problemas de forma autónoma, creativa y está capacitado para colaborar con su entorno laboral y en la organización del trabajo" (Echeverría, 2001).

Si cuestionásemos a un empresario cualquiera que entiende por un trabajador competente, la respuesta seria muy simple: "alguien que hace bien su trabajo". Son sólo seis palabras que engloban todo un desarrollo educativo que capacita a una persona para una determinada función. Saber hacer bien un trabajo implica llevar los conocimientos a la práctica, capacidad de organización y planificación, de resolver problemas, de trabajar en grupo, etc, es decir, manejar toda una serie de parámetros que en un mercado de trabajo tan competitivo y cambiante como el actual son necesarios para mantener la empleabilidad. Ese es hoy en día el reto de las universidades: devolver a la sociedad profesionales competentes. Es fundamental que las universidades vinculen los procesos de enseñanza-aprendizaje a los requerimientos del mercado de trabajo, ya que la simple transmisión de conocimientos no es suficiente para cumplir las exigencias que se demandan.

El proyecto Tuning realiza una clasificación de las competencias en función de determinados aspectos (González y Wagenaar, 2006), y así tendríamos:

- Competencias generales: estarían compuestas por las habilidades necesarias para desarrollar cualquier labor profesional, y serían comunes para las diferentes titulaciones.

- Competencias específicas: son aquellas que tienen que ver con el perfil formativo específico del alumno, y particulares para cada titulación.

Los cambios tecnológicos podrían ocasionar que las competencias específicas queden obsoletas. Por el contrario, las competencias genéricas pueden ser más perdurables en el tiempo y favorecer el aprendizaje continuo (Corominas, 2001). 
El Comité de Gestión de Tuning (2006), distingue los siguientes tipos de competencias:

- Competencias instrumentales: cognoscitivas, metodológicas, destrezas tecnológicas y destrezas lingüísticas.

- Competencias interpersonales: entre ellas, la capacidad para el trabajo en equipo, capacidad crítica y autocrítica.

- Competencias sistémicas, que son las destrezas y habilidades que conciernen a los sistemas como totalidad. Son competencias que necesitan el desarrollo de las instrumentales y las interpersonales, ya que su base es la integración de las mismas.

Para ofrecer respuestas a los objetivos marcados en la declaración de Bolonia, más de 135 universidades trabajaron de manera conjunta ante la necesidad de implementar las pautas marcadas en dicha declaración, en el proyecto Tuning. Se generó un espacio que permitió "acordar", "templar" y "afinar" las estructuras educativas en cuanto a las titulaciones, de manera que pudieran ser comprendidas, comparadas y reconocidas en el área común europea. Tuning quiere reflejar esa idea de búsqueda de puntos de acuerdo, de convergencia y de entendimiento mutuo, para facilitar la comprensión de las estructuras educativas. Estos puntos de referencia identificados son precisos para tender los puentes que sirvan para el reconocimiento de las titulaciones (González, Wagenaar y Beneitone, 2004).

De las cuatro líneas de actuación del proyecto, la primera se dedicaría al aprendizaje en competencias específicas, y la segunda a las competencias genéricas. La finalidad es desarrollar perfiles profesionales como resultado del aprendizaje en competencias.

El proyecto Tuning consultó a graduados, académicos y empleadores de siete disciplinas sobre treinta competencias genéricas y específicas, evaluando su importancia y el nivel de logro conseguido. En concreto, las competencias más importantes de las que se cuestionaron a graduados y empleadores fueron las siguientes:

- Capacidad de aprender.

- Habilidades para resolver problemas.

- Aplicar los conocimientos a la práctica.

- Destreza para manejar información.

- Capacidad para el trabajo autónomo y en grupo.

- Adaptación a nuevas situaciones.

El proceso iniciado con Bolonia se funde con los planteamientos de la Estrategia de Lisboa, donde se fija como uno de los objetivos de la Unión Europea "ir hacia una economía basada en el conocimiento para obtener más y mejores empleos" (Consejo Europeo de Lisboa, 2000). El proyecto Tuning enlaza la Estrategia de Lisboa con el proceso de Bolonia, creando puentes entre las necesidades sociales y económicas y las respuestas ofrecidas por los sistemas educativos superiores. Educación y sociedad deben ir de la mano para conseguir una mayor generación y calidad en el empleo. 
La mayoría de los estudios analizados a continuación, coinciden en otorgar un papel fundamental a la adquisición de competencias genéricas, sin restar importancia a la adquisición de competencias específicas propias de cada perfil formativo. Aquellas que son comunes a una generalidad de ocupaciones, cobran mayor fuerza ya que permiten la adaptación a los cambios sociales, y por ende a las transformaciones de los sistemas productivos y el mercado de trabajo. Un estudio dirigido a estudiantes de último curso de la Diplomatura en Ciencias Empresariales de la Universidad de Girona (Corominas, 2011), sobre el grado de importancia e influencia de un grupo de competencias genéricas presentadas, evidencia un claro desajuste entre estas dos variables. Por término medio, las diferencias entre la importancia y el grado de adquisición oscilan entre uno y dos puntos a favor de la primera variable. Las mayores se encuentran en competencias relacionadas con la autoestima ó la responsabilidad, mientras que existen menores diferencias en trabajo en equipo o uso de la información. Estos datos ponen de manifiesto la necesidad de una intervención para corregir esos déficits.

Se constata que en el mercado de trabajo, el dominio de las competencias genéricas se hace fundamental y por el contrario existen superavits formativos en cuanto a conocimientos y competencias específicas. Es decir, las empresas demandan organización, trabajo en equipo, gestión eficiente del trabajo ó capacidades de comunicación (Luque, 2009).

Rodríguez y Vieira (2009), en un estudio sobre competencias realizado en la Universidad de León, destacan que en la universidad prima la formación teórica en detrimento de las prácticas vinculadas a la disciplina estudiada, es decir, a la adquisición competencial de aplicar los conocimientos a la práctica. Igualmente se afirma que la formación en competencias genéricas es más elevada que la formación en competencias específicas -hablando siempre de datos de ésta investigación en concreto y considerando la muestra del estudio en cuestión-.

Alonso-Martín (2010), en un análisis sobre competencias para alumnos de tercer curso de Psicología de la Universidad de Huelva, concluye que se deberían fomentar en mayor medida las competencias genéricas, sobre todo aquellas relacionadas con la motivación y el logro por el trabajo. De los resultados obtenidos, se desprende que los alumnos tienen un buen nivel en aquellas competencias que les capacitan para tareas profesionales, pero sin embargo se percibe un menor desarrollo de competencias genéricas como organización, planificación y trabajo autónomo.

En el ámbito académico se le otorga una mayor importancia a los conocimientos teóricos y a competencias instrumentales como idiomas e informática, mientras que en el ámbito laboral cobran mayor importancia aquellas competencias relacionadas con aspectos sociales, organizacionales y de gestión del trabajo, es decir aquellas a las que el proyecto Tuning se refiere como competencias sistémicas, ya que flexibilizan la reconversión de los trabajadores, según una valoración sobre las competencias para el empleo realizado en la Universidad de La Laguna (Ramírez y Velázquez, 2010). 
Según Martínez (2010), en un estudio sobre el grado de ajuste entre el perfil competencial demandado por las empresas, y el obtenido por estudiantes de Administración y Dirección de Empresas de ICADE, las universidades se centran en trabajar los conocimientos teóricos y competencias específicas, mientras que los profesionales valoran más una mayor atención a las competencias genéricas. Concretamente se comparó el nivel competencial de los alumnos, con el perfil que requiere el mercado de trabajo. Se realizaron cuatro cuestionarios: el primero dirigido a empresas empleadoras de este perfil profesional, el segundo a egresados, el tercero a estudiantes del último curso y finalmente otro dirigido a profesores. Los alumnos otorgan tanto al nivel que creen que poseen de las competencias analizadas como a su importancia una puntuación menor que las obtenidas por profesores y profesionales. Los profesionales, argumentan que los recién licenciados al ingresar en una empresa, requieren un mayor dominio de competencias genéricas, orientadas al trabajo de una organización determinada, por ello en las encuestas son los egresados los que valoren más la formación en competencias.

Nuestro estudio, se propone como objetivo determinar la importancia que los alumnos atribuyen a un grupo de competencias seleccionadas, así como el grado de adquisición que creen poseer de cada una de ellas. Los resultados nos pueden permitir contestar a varios interrogantes: ¿qué tipo de competencias consideran los alumnos más importantes en su desarrollo formativo universitario?, ¿existe desajuste entre la importancia atribuida y el grado de adquisición que poseen en función de la formación recibida? Si realmente existen esas carencias y si los estudiantes demandan una mayor atención en unas competencias que en otras habría que implementar medidas para corregir esos desequilibrios.

Partiendo de los datos obtenidos en las investigaciones reseñadas anteriormente, podremos formular nuestra hipótesis de partida, que no es otra que comprobar si existe un desajuste entre la importancia y el grado de adquisición de las competencias estudiadas. Igualmente podremos comprobar si existen diferencias estadísticamente significativas, en función de la situación personal y académica de los alumnos encuestados.

\section{2.- METODOlOGía DE LA INVESTIGACIÓN}

Las competencias seleccionadas para realizar las encuestas, han sido extraídas del Libro Blanco "Título de Grado en Ciencias Laborales y Recursos Humanos" (2006). Tal como señala la memoria para la verificación del título oficial de Graduado/a en Relaciones Laborales y Recursos Humanos de la Universidad de Huelva, la capacitación para obtener la titulación debe garantizar que el alumno adquiera una serie de competencias necesarias para un futuro desarrollo de su carrera profesional.

Se han seleccionado 20 competencias de entre las recogidas en el mencionado documento. Según los datos de las investigaciones reseñadas, parece clara la importancia de las competencias genéricas en favor de una formación que permita a los estudiantes la adaptación a los cambios en su futura inserción en el mercado de trabajo. 
Por ello de las 20 competencias seleccionadas para el estudio, 15 son genéricas, 3 transversales y dos específicas propias de la titulación objeto de estudio, y a nuestro juicio fundamentales en la formación de los estudiantes.

1. CG2.1 Capacidad de organización y planificación.

2. CG2.2Capacidad de resolver problemas con información cualitativa y cuantitativa.

3. CG2.3Capacidad para aplicar los conocimientos a la práctica en sus diversos ámbitos de actuación.

4. CG2.4. Habilidad para el diseño y gestión de proyectos.

5. CG7 Capacidad de gestión de información.

6. CG8. Conocimientos de informática relativos al ámbito de estudio.

7. CG9. Capacidad de autocontrol, perseverancia, y un compromiso ético para colaborar en una sociedad más justa.

8. CG10. Capacidad de razonamiento crítico y autocrítico.

9. CG11. Capacidad de generar nuevas ideas.

10. CG12. Destrezas para transmitir información e ideas a un público tanto especializado como no especializado.

11. CG13. Habilidades en las relaciones interpersonales.

12. CG14. Trabajo en Grupo.

13. CG15. Trabajo en equipo de carácter interdisciplinar.

14. CG16. Capacidad de comunicación con otras áreas de conocimiento.

15. CG17. Análisis crítico de las decisiones emanadas de los agentes que participan en las relaciones laborales.

16. CE29.Aplicar los conocimientos a la práctica.

17. CE30. Capacidad para comprender la relación entre procesos sociales y la dinámica de las relaciones laborales.

18. CT1. Utilizar y aplicar las TICs, para aprender, comunicarse y compartir conocimientos en diferentes contextos.

19. CT2. Habilidades para la búsqueda activa de empleo y la capacidad de emprendimiento.

20. CT3. Capacidad de comunicación en una segunda lengua.

\section{1.- Sujetos}

La muestra estuvo formada por 41 alumnos del segundo curso del Grado en Relaciones Laborales y Recursos Humanos de la Universidad de Huelva, de los cuales el 70\% eran mujeres y el 30\% hombres, con edades comprendidas entre los 20 y los 27 años. Según los estudios de procedencia para acceso al grado, el 68\% provenían de bachillerato y 32\% de grados superiores relacionados con la disciplina objeto de sus estudios. Se han establecido distinciones según la situación de los encuestados en función de su actividad: el 19,5\% estudian y trabajan, el 22\% estudian y buscan 
empleo y el 58,5\% se dedican exclusivamente al estudio. Por último, se han separado por tramos según las asignaturas pendientes, para comprobar si pudiese tener alguna incidencia en cuanto al resultado de las encuestas, y así: el 41,4\% tienen 3 o más asignaturas pendientes del curso anterior; un 29,3\% una ó 2 y un 29,3\% ninguna.

\section{2.- INSTRUMENTO UTILIZADO}

El instrumento utilizado ha sido elaborado mediante un doble cuestionario con ítems de escala tipo Likert, con ocho valores, entre 1 y 8 . En el primero, los alumnos valoraron la importancia que les otorgan a las veinte competencias analizadas de cara al futuro desarrollo profesional de su carrera y en el segundo puntúan en función del nivel que creen que poseen de las mismas.

Las encuestas fueron realizadas el día 27 de Marzo de 2012 en el aula I.1.2 de la Facultad de Ciencias del Trabajo de la Universidad de Huelva. La batería de competencias analizadas se pasó previamente a consulta de un grupo de profesores de la Universidad de Huelva, para conocer su opinión sobre su confección. Una vez pasado el cuestionario a los alumnos, se omitió la competencia C3 por su semejanza con la número 16. Así mismo se ha evaluado la fiabilidad del mismo por el procedimiento alfa de Crombach obteniendo un valor de 0,892 . Por tanto el instrumento que estamos analizando es fiable, y podremos realizar mediciones estables y consistentes.

Los análisis estadísticos se realizaron con el programa SPSS versión 20. En principio se efectuaron análisis descriptivos de los bloques de variables (medias, desviaciones típicas y medias descendentes), para comparar las medias de las distintas variables. El contraste de hipótesis se realizó mediante la T de Student (en el caso de dos variables independientes). En los casos en los que la comparación de medias se realizó con tres o más variables, se utilizó el procedimiento de análisis de la varianza (Anova), ya que permite no sólo saber si hay diferencias entre las medias de los diferentes grupos, sino determinar entre qué grupos concretos se encuentras esas diferencias.

\section{3. - RESULTADOS OBTENIDOS}

Se han introducido diferentes variables para realizar contrastes en función de las distintas situaciones o estados de los individuos. Primeramente, se han clasificado las competencias en función de la importancia que los alumnos les otorgan y después, según el grado de adquisición que creen poseer de cada una de ellas, para realizar posteriormente una comparación por pares de ambas variables. Seguidamente se efectuaron comparaciones en función del sexo, edad, asignaturas pendientes, estudios de procedencia o su posicionamiento en el mercado laboral: si trabajan, sólo estudian o si se encuentran en proceso de búsqueda de empleo. El objetivo es conocer a qué competencias otorgan una mayor importancia los estudiantes, y cuál es el nivel que consideran haber adquirido hasta el momento en cada una de ellas. Realizando una 
comparación entre las dos variables, podremos obtener resultados que nos indiquen si se está prestando poca atención a competencias que los alumnos consideran de mayor importancia, o si por el contrario se produce una mayor concentración de esfuerzos encaminados a que los estudiantes adquieran competencias que consideran de menor importancia de cara a su futuro desarrollo profesional.

\section{1.- IMPORTANCIA Y NIVEL DE ADQUiSICIÓN DE LAS COMPETENCIAS ANALIZADAS}

Según la importancia que los alumnos creen que deben tener cada competencia de cara a su futuro desarrollo profesional (tabla $n^{\circ} 1$ ), la valoración más alta le corresponde a la competencia C16 (aplicar los conocimientos la práctica), seguida de la C20 (capacidad de comunicación en una segunda lengua), y la C19 (habilidades para la búsqueda activa de empleo). Por el contrario le conceden menor importancia a la C4 (habilidades para el diseño y gestión de proyectos) y a la C13 (trabajo en equipo de carácter multidisciplinar).

La competencias en las que creen tener un mayor nivel de adquisición (tabla n²) son la C12 (trabajo en grupo), C13 (trabajo en equipo de carácter multidisciplinar) y la C16 (aplicar los conocimientos a la práctica). Entre las que consideran que han adquirido un menor nivel, se encuentran la C20 (capacidad de comunicación en una segunda lengua), C4 (habilidad para el diseño y gestión de proyectos) y la C10 (destrezas para transmitir información e ideas en público).

TABLA $N^{\circ}$ 1. IMPORTANCIA OTORGADA

\begin{tabular}{|c|c|c|}
\hline Competencia & Media & Desv. Típ. \\
\hline IC16 & 7,41 & 0,865 \\
\hline IC20 & 7,34 & 1,153 \\
\hline IC3 & 7,27 & 1,049 \\
\hline IC19 & 7,22 & 0,988 \\
\hline IC10 & 7,02 & 1,458 \\
\hline IC9 & 6,95 & 1,264 \\
\hline IC1 & 6,95 & 0,999 \\
\hline IC12 & 6,88 & 1,053 \\
\hline IC2 & 6,88 & 1,053 \\
\hline IC7 & 6,85 & 1,295 \\
\hline IC5 & 6,85 & 1,062 \\
\hline IC6 & 6,83 & 1,022 \\
\hline IC11 & 6,8 & 1,077 \\
\hline IC18 & 6,8 & 0,928 \\
\hline IC8 & 6,73 & 1,119 \\
\hline IC15 & 6,61 & 1,243 \\
\hline IC17 & 6,59 & 1,36 \\
\hline IC14 & 6,37 & 1,178 \\
\hline IC13 & 6,34 & 1,353 \\
\hline IC4 & 6,22 & 1,173 \\
\hline
\end{tabular}

TABla No 2. Nivel de AdQuisición

\begin{tabular}{|c|c|c|}
\hline Competencia & Media & Desv. Típ. \\
\hline NC12 & 6,41 & 1,378 \\
\hline NC13 & 5,83 & 1,34 \\
\hline NC16 & 5,59 & 1,431 \\
\hline NC5 & 5,37 & 1,299 \\
\hline NC11 & 5,29 & 1,521 \\
\hline NC1 & 5,29 & 1,365 \\
\hline NC9 & 5,29 & 1,487 \\
\hline NC2 & 5,17 & 1,138 \\
\hline NC3 & 5,12 & 1,1 \\
\hline NC15 & 5,07 & 1,523 \\
\hline NC7 & 5,02 & 1,62 \\
\hline NC8 & 4,98 & 1,475 \\
\hline NC17 & 4,95 & 1,244 \\
\hline NC18 & 4,93 & 1,439 \\
\hline NC19 & 4,9 & 1,685 \\
\hline NC6 & 4,88 & 1,52 \\
\hline NC14 & 4,83 & 1,34 \\
\hline NC10 & 4,76 & 1,609 \\
\hline NC4 & 4,37 & 1,593 \\
\hline NC20 & 3,37 & 2,222 \\
\hline
\end{tabular}


En la tabla n³ observamos la comparación por pares de las muestras relacionadas. En este punto podríamos determinar si se corresponden las necesidades de los alumnos con el nivel competencial adquirido. Existen diferencias estadísticamente significativas en todas las competencias, a excepción de la C13 (trabajo en equipo de carácter interdisciplinar).

La menor diferencia se encuentra en la competencia C12 (trabajo en grupo). Donde existe una brecha mayor, es en las competencias: C20 (capacidad de comunicación en una segunda lengua), C19 (habilidades para la búsqueda activa de empleo), C10 (destrezas para transmitir información e ideas en público) y en menor medida la C6 (conocimientos de informática relativos al ámbito de estudio).

Tabla $\mathrm{N}^{\mathrm{O}}$ 3. Prueba de muestras relacionadas

\begin{tabular}{|c|c|c|c|c|c|}
\hline & & & $\begin{array}{l}\text { Diferencia } \\
\text { de medias }\end{array}$ & $\mathbf{t}$ & Sig \\
\hline \multirow{2}{*}{ Par 20} & IC20 & 7,34 & \multirow{2}{*}{3,976} & \multirow{2}{*}{10,415} & \multirow{2}{*}{ * } \\
\hline & NC20 & 3,37 & & & \\
\hline \multirow{2}{*}{ Par 19} & IC19 & 7,22 & \multirow{2}{*}{2,317} & \multirow{2}{*}{6,939} & \multirow{2}{*}{ * } \\
\hline & NC19 & 4,90 & & & \\
\hline \multirow{2}{*}{ Par 10} & IC10 & 7,02 & \multirow{2}{*}{2,268} & \multirow{2}{*}{6,884} & \multirow{2}{*}{ * } \\
\hline & NC10 & 4,76 & & & \\
\hline \multirow{2}{*}{ Par 3} & IC3 & 7,27 & \multirow{2}{*}{2,146} & \multirow{2}{*}{10,609} & \multirow{2}{*}{ * } \\
\hline & NC3 & 5,12 & & & \\
\hline \multirow{2}{*}{ Par 6} & IC6 & 6,83 & \multirow{2}{*}{1,951} & \multirow{2}{*}{7,47} & \multirow{2}{*}{ * } \\
\hline & NC6 & 4,88 & & & \\
\hline \multirow{2}{*}{ Par 18} & IC18 & 6,80 & \multirow{2}{*}{1,878} & \multirow{2}{*}{6,932} & \multirow{2}{*}{ * } \\
\hline & $\mathrm{NC} 18$ & 4,93 & & & \\
\hline \multirow{2}{*}{ Par 4} & IC4 & 6,22 & \multirow{2}{*}{1,854} & \multirow{2}{*}{7,121} & \multirow{2}{*}{ * } \\
\hline & NC4 & 4,37 & & & \\
\hline \multirow{2}{*}{ Par 7} & IC7 & 6,85 & \multirow{2}{*}{1,829} & \multirow{2}{*}{6,453} & \multirow{2}{*}{ * } \\
\hline & $\mathrm{NC7}$ & 5,02 & & & \\
\hline \multirow{2}{*}{ Par 16} & IC16 & 7,41 & \multirow{2}{*}{1,829} & 7069 & * \\
\hline & NC16 & 5,59 & & , & 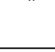 \\
\hline & IC8 & 6,73 & & & * \\
\hline Par 8 & NC8 & 4,98 & $1, / 56$ & 7,78 & 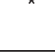 \\
\hline Par 2 & IC2 & 6,88 & 1.707 & 8,61 & * \\
\hline rar 2 & $\mathrm{NC2}$ & 5,17 & , & 8,01 & \\
\hline Par 1 & IC1 & 6,95 & 1659 & 7453 & * \\
\hline Tai t & $\mathrm{NC1}$ & 5,29 & (,000 & 1,400 & \\
\hline
\end{tabular}




\begin{tabular}{|c|c|c|c|c|c|}
\hline \multirow{2}{*}{ Par 9} & IC9 & 6,95 & \multirow{2}{*}{1,659} & \multirow{2}{*}{6,1} & \multirow{2}{*}{ * } \\
\hline & NC9 & 5,29 & & & \\
\hline \multirow{2}{*}{ Par 17} & IC17 & 6,59 & \multirow{2}{*}{1,634} & \multirow{2}{*}{7,422} & \multirow{2}{*}{ * } \\
\hline & NC17 & 4,95 & & & \\
\hline \multirow{2}{*}{ Par 14} & IC14 & 6,37 & \multirow{2}{*}{1,537} & \multirow{2}{*}{6,412} & \multirow{2}{*}{ * } \\
\hline & $\mathrm{NC14}$ & 4,83 & & & \\
\hline \multirow{2}{*}{ Par 15} & IC15 & 6,61 & \multirow{2}{*}{1,537} & \multirow{2}{*}{5,982} & \multirow{2}{*}{ * } \\
\hline & NC15 & 5,07 & & & \\
\hline \multirow{2}{*}{ Par 11} & IC11 & 6,80 & \multirow{2}{*}{1,512} & \multirow{2}{*}{5,539} & \multirow{2}{*}{ * } \\
\hline & $\mathrm{NC11}$ & 5,29 & & & \\
\hline \multirow{2}{*}{ Par 5} & IC5 & 6,85 & \multirow{2}{*}{1,488} & \multirow{2}{*}{6,726} & \multirow{2}{*}{ * } \\
\hline & NC5 & 5,37 & & & \\
\hline \multirow{2}{*}{ Par 13} & IC13 & 6,34 & \multirow{2}{*}{0,512} & \multirow{2}{*}{1,764} & \\
\hline & $\mathrm{NC13}$ & 5,83 & & & \\
\hline \multirow{2}{*}{ Par 12} & IC12 & 6,88 & \multirow{2}{*}{0,463} & \multirow{2}{*}{2,273} & \multirow{2}{*}{ * } \\
\hline & NC12 & 6,41 & & & \\
\hline
\end{tabular}

*Nivel de significación inferior al 0,05

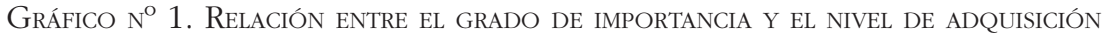



\section{2.- DIFERENCIAS POR SEXO}

Por sexo, se han encontrado en general pocas diferencias en la importancia otorgada a las siguientes competencias: C1 (capacidad de organización y planificación), C5 (capacidad de gestión de la información), C16 (aplicar los conocimientos a la práctica), C17 (comprensión de los procesos sociales y dinámicas de las relaciones laborales) y C18 (utilización y aplicación de las TIC,s). En todas son las mujeres las que le otorgan una mayor importancia. No se han encontrado diferencias significativas por sexo en cuanto al nivel de adquisición. 
TABla No 4. DifERENCIAS POR SEXO

\begin{tabular}{|c|c|c|c|c|c|c|c|}
\hline & & \multicolumn{3}{|c|}{ IMPORTANCIA } & \multicolumn{3}{|c|}{ ADQUISICIÓN } \\
\hline Competencia & Sexo & Media & $t$ & Sig & Media & $t$ & Sig \\
\hline $\mathrm{C} 1$ & $\begin{array}{c}\text { Hombre } \\
\text { Mujer }\end{array}$ & $\begin{array}{l}6,17 \\
7,28\end{array}$ & $-3,718$ & * & $\begin{array}{l}5,08 \\
5,38\end{array}$ & $-0,627$ & \\
\hline $\mathrm{C} 2$ & $\begin{array}{c}\text { Hombre } \\
\text { Mujer }\end{array}$ & $\begin{array}{c}6,58 \\
7\end{array}$ & $-1,157$ & & $\begin{array}{l}5,67 \\
4,97\end{array}$ & 1,848 & \\
\hline C3 & $\begin{array}{c}\text { Hombre } \\
\text { Mujer }\end{array}$ & $\begin{array}{l}6,67 \\
7,52\end{array}$ & $-1,949$ & & $\begin{array}{l}5,25 \\
5,07\end{array}$ & 0,475 & \\
\hline $\mathrm{C} 4$ & $\begin{array}{c}\text { Hombre } \\
\text { Mujer }\end{array}$ & $\begin{array}{l}5,75 \\
6,41\end{array}$ & $-1,686$ & & $\begin{array}{l}, 83 \\
4,59\end{array}$ & $-1,393$ & \\
\hline C5 & $\begin{array}{c}\text { Hombre } \\
\text { Mujer }\end{array}$ & $\begin{array}{l}6,33 \\
7,07\end{array}$ & $-2,102$ & * & $\begin{array}{l}5,67 \\
5,24\end{array}$ & 0,953 & \\
\hline C6 & $\begin{array}{c}\text { Hombre } \\
\text { Mujer }\end{array}$ & $\begin{array}{l}6,75 \\
6,86\end{array}$ & $-0,255$ & & $\begin{array}{c}4,58 \\
5\end{array}$ & $-0,795$ & \\
\hline C7 & $\begin{array}{c}\text { Hombre } \\
\text { Mujer }\end{array}$ & $\begin{array}{l}6,83 \\
6,86\end{array}$ & $-0,064$ & & $\begin{array}{l}4,75 \\
5,14\end{array}$ & $-0,693$ & \\
\hline $\mathrm{C} 8$ & $\begin{array}{c}\text { Hombre } \\
\text { Mujer }\end{array}$ & $\begin{array}{l}6,25 \\
6,93\end{array}$ & $-1,484$ & & $\begin{array}{c}4,92 \\
5\end{array}$ & $-0,163$ & \\
\hline C9 & $\begin{array}{c}\text { Hombre } \\
\text { Mujer }\end{array}$ & $\begin{array}{l}7,42 \\
6,76\end{array}$ & 1,543 & & $\begin{array}{l}5,42 \\
5,24\end{array}$ & 0,340 & \\
\hline C10 & $\begin{array}{c}\text { Hombre } \\
\text { Mujer }\end{array}$ & $\begin{array}{c}7,08 \\
7\end{array}$ & 0,165 & & $\begin{array}{c}5 \\
4,66 \\
\end{array}$ & 0,620 & \\
\hline C11 & $\begin{array}{c}\text { Hombre } \\
\text { Mujer }\end{array}$ & $\begin{array}{c}6,33 \\
7\end{array}$ & $-1,857$ & & $\begin{array}{l}4,83 \\
5,48\end{array}$ & $-1,253$ & \\
\hline C12 & $\begin{array}{c}\text { Hombre } \\
\text { Mujer }\end{array}$ & $\begin{array}{c}6,83 \\
6,9\end{array}$ & $-0,173$ & & $\begin{array}{l}6,58 \\
6,34\end{array}$ & 0,500 & \\
\hline C13 & $\begin{array}{c}\text { Hombre } \\
\text { Mujer }\end{array}$ & $\begin{array}{c}6 \\
6,48\end{array}$ & $-1,041$ & & $\begin{array}{c}5,67 \\
5,9\end{array}$ & $-0,495$ & \\
\hline C14 & $\begin{array}{c}\text { Hombre } \\
\text { Mujer }\end{array}$ & $\begin{array}{c}6 \\
6,52\end{array}$ & $-1,290$ & & $\begin{array}{l}4,58 \\
4,93\end{array}$ & $-0,752$ & \\
\hline C15 & $\begin{array}{c}\text { Hombre } \\
\text { Mujer }\end{array}$ & $\begin{array}{c}6,5 \\
6,66\end{array}$ & $-0,360$ & & $\begin{array}{c}5,25 \\
5\end{array}$ & 0,474 & \\
\hline C16 & $\begin{array}{c}\text { Hombre } \\
\text { Mujer }\end{array}$ & $\begin{array}{c}7 \\
7,59\end{array}$ & $-2,051$ & * & $\begin{array}{l}6,08 \\
5,38\end{array}$ & 1,453 & \\
\hline C17 & $\begin{array}{c}\text { Hombre } \\
\text { Mujer }\end{array}$ & $\begin{array}{l}5,75 \\
6,93\end{array}$ & $-2,726$ & * & $\begin{array}{c}4,83 \\
5\end{array}$ & $-0,529$ & \\
\hline C18 & $\begin{array}{c}\text { Hombre } \\
\text { Mujer }\end{array}$ & $\begin{array}{l}6,25 \\
7,03\end{array}$ & $-2,641$ & * & $\begin{array}{c}5 \\
4,9\end{array}$ & 0,207 & \\
\hline C19 & $\begin{array}{c}\text { Hombre } \\
\text { Mujer }\end{array}$ & $\begin{array}{l}7,08 \\
7,28\end{array}$ & $-0,563$ & & $\begin{array}{l}5,42 \\
4,69\end{array}$ & 1,266 & \\
\hline C20 & $\begin{array}{c}\text { Hombre } \\
\text { Mujer }\end{array}$ & $\begin{array}{l}7,33 \\
7,34\end{array}$ & $-0,029$ & & $\begin{array}{l}2,92 \\
3,55\end{array}$ & $-0,829$ & \\
\hline
\end{tabular}

*Nivel de significación inferior al 0,05

\section{3.- Diferencias Según los estudios de acCeso Al GRAdo}

Dependiendo de los estudios anteriores cursados por los alumnos, se han encontrado en general pocas diferencias en el nivel de competencial adquirido entre los alumnos que provienen de bachillerato y los de grados superiores de formación profesional en las siguientes competencias: C7 (capacidad de autocontrol, perseverancia y 
compromiso ético para colaborar en una sociedad más justa) y en la C19 (habilidades para la búsqueda activa de empleo; en las dos competencias señaladas los alumnos que otorgan mayor valor a la adquisición son los que provienen de bachillerato.

Tabla N ${ }^{\circ}$ 5. Diferencias según los estudios de acCeso al Grado

\begin{tabular}{|c|c|c|c|c|c|c|c|}
\hline & & \multicolumn{2}{|c|}{ IMPORTANCIA } & \multicolumn{4}{|c|}{ ADQUISICIÓN } \\
\hline Competencia & Estudios & Media & $t$ & Sig & Media & $\mathbf{t}$ & Sig \\
\hline C1 & Bachillerato & 6,790 & $-1,586$ & & 5,140 & $-1,033$ & \\
\hline $\mathrm{C} 2$ & $\begin{array}{l}\text { Bachillerato } \\
\text { Grado de FP }\end{array}$ & $\begin{array}{l}6,890 \\
6,850\end{array}$ & 0,130 & & $\begin{array}{l}5,180 \\
5,150\end{array}$ & 0,064 & \\
\hline C3 & $\begin{array}{l}\text { Bachillerato } \\
\text { Grado de FP }\end{array}$ & $\begin{array}{l}7,250 \\
7,310\end{array}$ & $-0,162$ & & $\begin{array}{l}5,360 \\
4,620 \\
\end{array}$ & 2,093 & \\
\hline $\mathrm{C} 4$ & $\begin{array}{l}\text { Bachillerato } \\
\text { Grado de FP }\end{array}$ & $\begin{array}{l}6,320 \\
6,000\end{array}$ & 0,813 & & $\begin{array}{l}4,570 \\
3,920\end{array}$ & 1,220 & \\
\hline C5 & $\begin{array}{l}\text { Bachillerato } \\
\text { Grado de FP }\end{array}$ & $\begin{array}{l}6,710 \\
7,150\end{array}$ & $-1,241$ & & $\begin{array}{l}5,460 \\
5,150\end{array}$ & 0,708 & \\
\hline C6 & $\begin{array}{l}\text { Bachillerato } \\
\text { Grado de FP }\end{array}$ & $\begin{array}{l}6,820 \\
6,850\end{array}$ & $-0,071$ & & $\begin{array}{l}4,820 \\
5,000\end{array}$ & $-0,346$ & \\
\hline $\mathrm{C7}$ & $\begin{array}{l}\text { Bachillerato } \\
\text { Grado de FP }\end{array}$ & $\begin{array}{l}6,820 \\
6,920\end{array}$ & $-0,231$ & & $\begin{array}{l}5,460 \\
4,080 \\
\end{array}$ & 2,754 & * \\
\hline C8 & $\begin{array}{l}\text { Bachillerato } \\
\text { Grado de FP }\end{array}$ & $\begin{array}{l}6,610 \\
7,000\end{array}$ & $-1,048$ & & $\begin{array}{l}5,180 \\
4,540\end{array}$ & 1,305 & \\
\hline C9 & $\begin{array}{l}\text { Bachillerato } \\
\text { Grado de FP }\end{array}$ & $\begin{array}{l}6,890 \\
7,080\end{array}$ & $-0,429$ & & $\begin{array}{l}5,360 \\
5,150\end{array}$ & 0,403 & \\
\hline C10 & $\begin{array}{l}\text { Bachillerato } \\
\text { Grado de FP }\end{array}$ & $\begin{array}{l}7,000 \\
7,080\end{array}$ & $-0,155$ & & $\begin{array}{l}4,790 \\
4,690\end{array}$ & 0,171 & \\
\hline C11 & $\begin{array}{l}\text { Bachillerato } \\
\text { Grado de FP }\end{array}$ & $\begin{array}{l}6,820 \\
6,770\end{array}$ & 0,143 & & $\begin{array}{l}5,460 \\
4,920 \\
\end{array}$ & 1,062 & \\
\hline C12 & $\begin{array}{l}\text { Bachillerato } \\
\text { Grado de FP }\end{array}$ & $\begin{array}{l}6,960 \\
6,690 \\
\end{array}$ & 0,765 & & $\begin{array}{l}6,540 \\
6,150\end{array}$ & 0,822 & \\
\hline C13 & $\begin{array}{l}\text { Bachillerato } \\
\text { Grado de FP }\end{array}$ & $\begin{array}{l}6,500 \\
6,000\end{array}$ & 1,104 & & $\begin{array}{l}5,820 \\
5,850 \\
\end{array}$ & $-0,054$ & \\
\hline C14 & $\begin{array}{l}\text { Bachillerato } \\
\text { Grado de FP }\end{array}$ & $\begin{array}{l}6,390 \\
6,310\end{array}$ & 0,213 & & $\begin{array}{l}4,930 \\
4,620 \\
\end{array}$ & 0,692 & \\
\hline C15 & $\begin{array}{l}\text { Bachillerato } \\
\text { Grado de FP }\end{array}$ & $\begin{array}{l}6,570 \\
6,690 \\
\end{array}$ & $-0,287$ & & $\begin{array}{l}5,110 \\
5,000 \\
\end{array}$ & 0,207 & \\
\hline C16 & $\begin{array}{l}\text { Bachillerato } \\
\text { Grado de FP }\end{array}$ & $\begin{array}{l}7,390 \\
7,460\end{array}$ & $-0,234$ & & $\begin{array}{l}5,790 \\
5,150\end{array}$ & 1,328 & \\
\hline C17 & $\begin{array}{l}\text { Bachillerato } \\
\text { Grado de FP }\end{array}$ & $\begin{array}{l}6,500 \\
6,770 \\
\end{array}$ & $-0,585$ & & $\begin{array}{l}5,140 \\
4,540 \\
\end{array}$ & 1,243 & \\
\hline C18 & $\begin{array}{l}\text { Bachillerato } \\
\text { Grado de FP }\end{array}$ & $\begin{array}{l}6,960 \\
6,460\end{array}$ & 1,649 & & $\begin{array}{l}5,110 \\
4,540 \\
\end{array}$ & 1,184 & \\
\hline C19 & $\begin{array}{l}\text { Bachillerato } \\
\text { Grado de FP }\end{array}$ & $\begin{array}{l}7,210 \\
7,230 \\
\end{array}$ & 0,826 & & $\begin{array}{l}5,290 \\
4,080 \\
\end{array}$ & 2,242 & * \\
\hline $\mathrm{C} 20$ & $\begin{array}{l}\text { Bachillerato } \\
\text { Grado de FP }\end{array}$ & $\begin{array}{l}7,540 \\
6,920\end{array}$ & 0,131 & & $\begin{array}{l}3,360 \\
3,380\end{array}$ & $-0,036$ & \\
\hline
\end{tabular}

*Nivel de significación inferior al 0,05 


\section{4.- DifERENCIAS POR EDADES}

Tan solo hemos encontrado diferencias estadísticamente significativas por edades en la importancia otorgada a la competencia 19 (habilidades para la búsqueda activa de empleo), concretamente las diferencias se encuentran entre los tramos de edad de 22 a 24 y de 25 a 28 , siendo los alumnos del tramo superior los que consideran más importante esta competencia.

TABla N ${ }^{0}$ 6. Diferencias Por eDades

\begin{tabular}{|c|c|c|c|c|c|c|c|}
\hline \multirow[b]{2}{*}{ Competencia } & \multirow[b]{2}{*}{$\begin{array}{l}\text { Tramos } \\
\text { edades }\end{array}$} & \multicolumn{3}{|c|}{ IMPORTANCIA } & \multicolumn{3}{|c|}{ ADQUISICIÓN } \\
\hline & & Media & $\begin{array}{c}\text { Desviación } \\
\text { típica }\end{array}$ & Sig & Media & $\begin{array}{c}\text { Desviación } \\
\text { típica }\end{array}$ & Sig \\
\hline \multirow[t]{3}{*}{ C1 } & \multirow{3}{*}{$\begin{array}{l}\text { 19-21 años } \\
22-24 \text { años } \\
25-28 \text { años }\end{array}$} & 6,94 & 0,998 & & 5,28 & 1,406 & \\
\hline & & 6,69 & 1,182 & & 4,85 & 1,573 & \\
\hline & & 7,3 & 0,675 & & 5,9 & 0,738 & \\
\hline $\mathrm{C} 2$ & 19-21 años & 6,94 & 1,162 & & 5 & 1,085 & \\
\hline \multirow[t]{2}{*}{ w } & 22-24 años & 6,85 & 1,068 & & 5 & 1,155 & \\
\hline & $25-28$ años & 6,8 & 0,919 & & 5,7 & 1,16 & \\
\hline \multirow[t]{3}{*}{ C3 } & 19-21 años & 7,67 & 0,485 & & 5,39 & 1,243 & \\
\hline & 22-24 años & 6,77 & 1,481 & & 4,69 & 0,855 & \\
\hline & $25-28$ años & 7,2 & 0,919 & & 5,2 & 1,033 & \\
\hline \multirow[t]{3}{*}{ IC4 } & 19-21 años & 6,22 & 1,166 & & 4,39 & 1,577 & \\
\hline & 22-24 años & 6,23 & 1,235 & & 3,85 & 0,801 & \\
\hline & 25-28 años & 6,2 & 1,229 & & 5 & 2,211 & \\
\hline \multirow[t]{3}{*}{ C5 } & 19-21 años & 6,72 & 1,074 & & 5,5 & 1,581 & \\
\hline & 22-24 años & 6,77 & 1,092 & & 5 & 1,08 & \\
\hline & 25-28 años & 7,2 & 1,033 & & 5,6 & 0,966 & \\
\hline \multirow[t]{3}{*}{ C6 } & 19-21 años & 6,94 & 0,725 & & 5,17 & 1,15 & \\
\hline & 22-24 años & 6,38 & 1,261 & & 4,46 & 1,761 & \\
\hline & $25-28$ años & 7,2 & 1,033 & & 4,9 & 1,792 & \\
\hline \multirow[t]{3}{*}{$\mathrm{C} 7$} & 19-21 años & 6,72 & 1,565 & & 5,5 & 1,505 & \\
\hline & 22-24 años & 6,69 & 1,182 & & 4,54 & 1,761 & \\
\hline & $25-28$ años & 7,3 & 0,823 & & 4,8 & 1,549 & \\
\hline \multirow[t]{3}{*}{ C8 } & 19-21 años & 6,78 & 1,06 & & 5,28 & 1,526 & \\
\hline & 22-24 años & 6,46 & 1,05 & & 4,92 & 1,553 & \\
\hline & $25-28$ años & 7 & 1,333 & & 4,5 & 1,269 & \\
\hline \multirow[t]{3}{*}{ C9 } & 19-21 años & 6,89 & 1,278 & & 5,28 & 1,447 & \\
\hline & $22-24$ años & 6,62 & 1,557 & & 5 & 1,291 & \\
\hline & $25-28$ años & 7,5 & 0,527 & & 5,7 & 1,829 & \\
\hline \multirow[t]{3}{*}{ C10 } & 19-21 años & 7,06 & 1,474 & & 4,56 & 1,822 & \\
\hline & 22-24 años & 6,77 & 1,641 & & 4,92 & 1,441 & \\
\hline & $25-28$ años & 7,3 & 1,252 & & 4,9 & 1,524 & \\
\hline C11 & 19-21 años & 6,94 & 1,056 & & 5,56 & 1,381 & \\
\hline
\end{tabular}




\begin{tabular}{|c|c|c|c|c|c|c|c|}
\hline \multirow[b]{2}{*}{ Competencia } & \multirow[b]{2}{*}{$\begin{array}{l}\text { Tramos } \\
\text { edades }\end{array}$} & \multicolumn{3}{|c|}{ IMPORTANCIA } & \multicolumn{3}{|c|}{ ADQUISICIÓN } \\
\hline & & Media & $\begin{array}{c}\text { Desviación } \\
\text { típica }\end{array}$ & Sig & Media & $\begin{array}{c}\text { Desviación } \\
\text { típica }\end{array}$ & Sig \\
\hline & \multirow{2}{*}{$\begin{array}{l}\text { 22-24 años } \\
25-28 \text { años }\end{array}$} & 6,46 & 1,266 & & 4,92 & 1,605 & \\
\hline & & 7 & 0,816 & & 5,3 & 1,703 & \\
\hline \multirow[t]{3}{*}{ C12 } & \multirow{3}{*}{$\begin{array}{l}\text { 19-21 años } \\
22-24 \text { años } \\
25-28 \text { años }\end{array}$} & 6,94 & 0,998 & & 6,61 & 1,29 & \\
\hline & & 6,62 & 1,121 & & 6,23 & 1,536 & \\
\hline & & 7,1 & 1,101 & & 6,3 & 1,418 & \\
\hline \multirow[t]{3}{*}{ C13 } & \multirow{3}{*}{$\begin{array}{l}\text { 19-21 años } \\
22-24 \text { años } \\
25-28 \text { años }\end{array}$} & 6,44 & 1,723 & & 6 & 1,495 & \\
\hline & & 6,23 & 1,013 & & 5,62 & 1,121 & \\
\hline & & 6,3 & 1,059 & & 5,8 & 1,398 & \\
\hline \multirow[t]{3}{*}{ C14 } & \multirow{3}{*}{$\begin{array}{l}19-21 \text { años } \\
22-24 \text { años } \\
25-28 \text { años }\end{array}$} & 6,33 & 1,455 & & 4,78 & 1,629 & \\
\hline & & 6,46 & 0,776 & & 5 & 1,291 & \\
\hline & & 6,3 & 1,16 & & 4,7 & 0,823 & \\
\hline \multirow[t]{3}{*}{ C15 } & \multirow{3}{*}{$\begin{array}{l}\text { 19-21 años } \\
22-24 \text { años } \\
25-28 \text { años }\end{array}$} & 6,61 & 1,378 & & 5,11 & 1,745 & \\
\hline & & 6,62 & 1,121 & & 4,85 & 1,214 & \\
\hline & & 6,6 & 1,265 & & 5,3 & 1,567 & \\
\hline \multirow[t]{3}{*}{ C16 } & \multirow{3}{*}{$\begin{array}{l}\text { 19-21 años } \\
22-24 \text { años } \\
25-28 \text { años }\end{array}$} & 7,56 & 0,856 & & 5,83 & 1,339 & \\
\hline & & 7 & 1 & & 5,31 & 1,182 & \\
\hline & & 7,7 & 0,483 & & 5,5 & 1,9 & \\
\hline \multirow[t]{3}{*}{ C17 } & \multirow{3}{*}{$\begin{array}{l}\text { 19-21 años } \\
22-24 \text { años } \\
25-28 \text { años }\end{array}$} & 6,33 & 1,715 & & 5,06 & 1,392 & \\
\hline & & 6,69 & 0,947 & & 4,92 & 0,862 & \\
\hline & & 6,9 & 1,101 & & 4,8 & 1,476 & \\
\hline \multirow[t]{3}{*}{ C18 } & \multirow{3}{*}{$\begin{array}{l}\text { 19-21 años } \\
22-24 \text { años } \\
25-28 \text { años }\end{array}$} & 7,17 & 0,786 & & 5 & 1,572 & \\
\hline & & 6,62 & 0,65 & & 5 & 1,225 & \\
\hline & & 6,4 & 1,265 & & 4,7 & 1,567 & \\
\hline \multirow[t]{3}{*}{ C19 } & \multirow{3}{*}{$\begin{array}{l}\text { 19-21 años } \\
22-24 \text { años } \\
25-28 \text { años }\end{array}$} & 7,33 & 0,84 & & 5 & 1,879 & \\
\hline & & 6,69 & 1,251 & * & 5,08 & 1,498 & \\
\hline & & 7,7 & 0,483 & * & 4,5 & 1,65 & \\
\hline \multirow[t]{3}{*}{$\mathrm{C} 20$} & 19-21 años & 7,67 & 0,594 & & 2,67 & 1,94 & \\
\hline & 22-24 años & 6,77 & 1,691 & & 3,54 & 2,295 & \\
\hline & 25-28 años & 7,5 & 0,85 & & 4,4 & 2,366 & \\
\hline
\end{tabular}

*Nivel de significación inferior al 0,05

3.5.- Diferencias según la situación de los estudiantes frente al mercado de trabajo

Encontramos diferencias estadísticamente significativas en la importancia otorgada a las siguientes competencias: C6 (conocimientos de informática relativo al ámbito de estudio), concretamente la diferencia se muestra entre los que estudian/trabajan y estudian/buscan empleo, concediéndole mayor importancia el segundo grupo, y en la C8 (capacidad de razonamiento crítico y autocrítico), entre los grupos estudia y estudia/ trabaja, concretamente el primer grupo le otorga una mayor importancia. 
TABla No 7 . Diferencias SEgún La Situación

\begin{tabular}{|c|c|c|c|c|c|c|c|}
\hline & & \multicolumn{3}{|c|}{ IMPORTANCIA } & \multicolumn{3}{|c|}{ ADQUISICIÓN } \\
\hline Competencia & Situación & Media & $\begin{array}{c}\text { Desviación } \\
\text { típica }\end{array}$ & Sig & Media & $\begin{array}{c}\text { Desviación } \\
\text { típica }\end{array}$ & Sig \\
\hline \multirow[t]{3}{*}{$\mathrm{C} 1$} & \multirow{3}{*}{$\begin{array}{c}\text { Estudia } \\
\text { Estudia y trabaja } \\
\begin{array}{c}\text { Estudia y busca } \\
\text { empleo }\end{array}\end{array}$} & 7,13 & 0,85 & & 5,63 & 1,313 & \\
\hline & & 7 & 0,756 & & 4,5 & 1,309 & \\
\hline & & 6,44 & 1,424 & & 5,11 & 1,364 & \\
\hline \multirow[t]{3}{*}{$\mathrm{C} 2$} & \multirow{3}{*}{$\begin{array}{c}\text { Estudia } \\
\text { Estudia y trabaja } \\
\text { Estudia y busca } \\
\text { empleo }\end{array}$} & 6,96 & 1,197 & & 5,17 & 1,167 & \\
\hline & & 7 & 0,535 & & 5 & 1,069 & \\
\hline & & 6,56 & 1,014 & & 5,33 & 1,225 & \\
\hline \multirow[t]{3}{*}{$\mathrm{C} 3$} & \multirow{3}{*}{$\begin{array}{c}\text { Estudia } \\
\text { Estudia y trabaja } \\
\text { Estudia y busca } \\
\text { empleo }\end{array}$} & 7,33 & 1,129 & & 5,25 & 1,113 & \\
\hline & & 7,25 & 1,035 & & 5 & 1,309 & \\
\hline & & 7,11 & 0,928 & & 4,89 & 0,928 & \\
\hline \multirow[t]{3}{*}{ IC4 } & \multirow{3}{*}{$\begin{array}{c}\text { Estudia } \\
\text { Estudia y trabaja } \\
\begin{array}{c}\text { Estudia y busca } \\
\text { empleo }\end{array}\end{array}$} & 6,25 & 1,359 & & 4,54 & 1,414 & \\
\hline & & 5,88 & 0,991 & & 4 & 1,773 & \\
\hline & & 6,44 & 0,726 & & 4,22 & 1,986 & \\
\hline \multirow[t]{3}{*}{ C5 } & \multirow{3}{*}{$\begin{array}{c}\text { Estudia } \\
\text { Estudia y trabaja } \\
\text { Estudia y busca } \\
\text { empleo }\end{array}$} & 6,92 & 1,018 & & 5,38 & 1,377 & \\
\hline & & 6,75 & 1,165 & & 5 & 1,414 & \\
\hline & & 6,78 & 1,202 & & 5,67 & 1 & \\
\hline \multirow[t]{3}{*}{$\mathrm{C} 6$} & \multirow{3}{*}{$\begin{array}{c}\text { Estudia } \\
\text { Estudia y trabaja } \\
\text { Estudia y busca } \\
\text { empleo }\end{array}$} & 6,79 & 0,977 & & 4,92 & 1,412 & \\
\hline & & 6,13 & 0,991 & * & 4,5 & 0,926 & \\
\hline & & 7,56 & 0,726 & * & 5,11 & 2,205 & \\
\hline \multirow[t]{3}{*}{$\mathrm{C} 7$} & \multirow{3}{*}{$\begin{array}{c}\text { Estudia } \\
\text { Estudia y trabaja } \\
\text { Estudia y busca } \\
\text { empleo }\end{array}$} & 7,08 & 1,139 & & 5,71 & 1,197 & \\
\hline & & 6 & 1,512 & & 3,25 & 1,165 & \\
\hline & & 7 & 1,323 & & 4,78 & 1,787 & \\
\hline \multirow[t]{3}{*}{$\mathrm{C} 8$} & \multirow{3}{*}{$\begin{array}{c}\text { Estudia } \\
\text { Estudia y trabaja } \\
\text { Estudia y busca } \\
\text { empleo }\end{array}$} & 6,96 & 1,16 & * & 5,33 & 1,659 & \\
\hline & & 5,88 & 0,641 & * & 4,25 & 0,886 & \\
\hline & & 6,89 & 1,054 & & 4,67 & 1,118 & \\
\hline \multirow[t]{3}{*}{$\mathrm{Cg}$} & \multirow{3}{*}{$\begin{array}{l}\text { Estudia } \\
\text { Estudia y trabaja } \\
\text { Estudia y busca }\end{array}$} & 7,08 & 1,349 & & 5,54 & 1,444 & \\
\hline & & 6,63 & 1,188 & & 4,88 & 0,835 & \\
\hline & & 6,89 & 1,167 & & 5 & 2 & \\
\hline
\end{tabular}




\begin{tabular}{|c|c|c|c|c|c|}
\hline C10 & Estudia & 7,38 & 0,924 & 4,79 & 1,615 \\
\hline & \multirow{2}{*}{$\begin{array}{c}\text { Estudia y trabaja } \\
\text { Estudia y busca } \\
\text { empleo }\end{array}$} & 6,75 & 1,832 & 4,75 & 1,282 \\
\hline & & 6,33 & 2,062 & 4,67 & 2 \\
\hline \multirow[t]{3}{*}{ C11 } & \multirow{3}{*}{$\begin{array}{c}\text { Estudia } \\
\text { Estudia y trabaja } \\
\text { Estudia y busca } \\
\text { empleo }\end{array}$} & 6,79 & 1,215 & 5,42 & 1,472 \\
\hline & & 6,88 & 0,991 & 4,38 & 1,302 \\
\hline & & 6,78 & 0,833 & 5,78 & 1,641 \\
\hline \multirow[t]{3}{*}{ C12 } & \multirow{3}{*}{$\begin{array}{c}\text { Estudia } \\
\text { Estudia y trabaja } \\
\text { Estudia y busca } \\
\text { empleo }\end{array}$} & 6,92 & 1,139 & 6,42 & 1,316 \\
\hline & & 6,75 & 1,035 & 6 & 1,512 \\
\hline & & 6,89 & 0,928 & 6,78 & 1,481 \\
\hline \multirow[t]{3}{*}{ C13 } & \multirow{3}{*}{$\begin{array}{c}\text { Estudia } \\
\text { Estudia y trabaja } \\
\begin{array}{c}\text { Estudia y busca } \\
\text { empleo }\end{array}\end{array}$} & 6,54 & 1,414 & 6 & 1,504 \\
\hline & & 6,13 & 1,356 & 5,5 & 0,926 \\
\hline & & 6 & 1,225 & 5,67 & 1,225 \\
\hline \multirow[t]{3}{*}{ C14 } & \multirow{3}{*}{$\begin{array}{c}\text { Estudia } \\
\text { Estudia y trabaja } \\
\text { Estudia y busca } \\
\text { empleo }\end{array}$} & 6,33 & 1,341 & 4,71 & 1,488 \\
\hline & & 6,63 & 0,916 & 4,63 & 0,916 \\
\hline & & 6,22 & 0,972 & 5,33 & 1,225 \\
\hline \multirow[t]{3}{*}{ C15 } & \multirow{3}{*}{$\begin{array}{c}\text { Estudia } \\
\text { Estudia y trabaja } \\
\text { Estudia y busca } \\
\text { empleo }\end{array}$} & 6,88 & 1,154 & 5,13 & 1,727 \\
\hline & & 6,5 & 1,195 & 5,13 & 1,246 \\
\hline & & 6 & 1,414 & 4,89 & 1,269 \\
\hline \multirow[t]{3}{*}{ C16 } & \multirow{3}{*}{$\begin{array}{c}\text { Estudia } \\
\text { Estudia y trabaja } \\
\text { Estudia y busca } \\
\text { empleo }\end{array}$} & 7,42 & 0,929 & 5,71 & 1,268 \\
\hline & & 7,13 & 0,991 & 5,75 & 1,165 \\
\hline & & 7,67 & 0,5 & 5,11 & 2,028 \\
\hline \multirow[t]{3}{*}{ C17 } & \multirow{3}{*}{$\begin{array}{c}\text { Estudia } \\
\text { Estudia y trabaja } \\
\text { Estudia y busca } \\
\text { empleo }\end{array}$} & 6,54 & 1,56 & 5,04 & 1,122 \\
\hline & & 6,75 & 1,282 & 5 & 1,512 \\
\hline & & 6,56 & 0,882 & 4,67 & 1,414 \\
\hline \multirow[t]{3}{*}{ C18 } & \multirow{3}{*}{$\begin{array}{c}\text { Estudia } \\
\text { Estudia y trabaja } \\
\text { Estudia y busca } \\
\text { empleo }\end{array}$} & 6,79 & 1,062 & 4,83 & 1,404 \\
\hline & & 7,38 & 0,518 & 5,63 & 1,061 \\
\hline & & 6,33 & 0,5 & 4,56 & 1,74 \\
\hline \multirow[t]{3}{*}{ C19 } & \multirow{3}{*}{$\begin{array}{c}\text { Estudia } \\
\text { Estudia y trabaja } \\
\text { Estudia y busca } \\
\text { empleo }\end{array}$} & 7,17 & 1,129 & 5,08 & 1,742 \\
\hline & & 7 & 0,926 & 4 & 1,069 \\
\hline & & 7,56 & 0,527 & 5,22 & 1,856 \\
\hline \multirow[t]{3}{*}{$\mathrm{C} 20$} & \multirow{3}{*}{$\begin{array}{c}\text { Estudia } \\
\text { Estudia y trabaja } \\
\text { Estudia y busca } \\
\text { empleo }\end{array}$} & 7,25 & 1,391 & 3,33 & 2,078 \\
\hline & & 7,38 & 0,744 & 3,38 & 2,615 \\
\hline & & 7,56 & 0,726 & 3,44 & 2,506 \\
\hline
\end{tabular}




\section{6.- Diferencias Según las asignaturas pendientes}

Por último, según las asignaturas pendientes, la única diferencia estadísticamente significativa la encontramos en la importancia referida a la competencia C6 (conocimientos de informática relativos al ámbito de estudio), donde los alumnos que no tienen ninguna asignatura pendiente les otorgan una mayor importancia que los del grupo de tres o más pendientes.

TABla No 8 . Diferencias Según las asignaturas Pendientes

\begin{tabular}{|c|c|c|c|c|c|c|c|}
\hline \multicolumn{5}{|c|}{ IMPORTANCIA } & \multicolumn{3}{|c|}{ ADQUISICIÓN } \\
\hline Competencia & $\begin{array}{c}\text { Asignaturas } \\
\text { pendientes }\end{array}$ & Media & $\begin{array}{c}\text { Desviación } \\
\text { típica }\end{array}$ & Sig & Media & $\begin{array}{l}\text { Desviación } \\
\text { típica }\end{array}$ & Sig \\
\hline \multirow[t]{3}{*}{$\mathrm{C} 1$} & \multirow{3}{*}{$\begin{array}{c}\text { ninguna } \\
1 \text { o } 2 \\
3 \text { o más }\end{array}$} & 7,33 & 0,985 & & 5,42 & 1,379 & \\
\hline & & 7 & 1,128 & & 5,42 & 1,443 & \\
\hline & & 6,65 & 0,862 & & 5,12 & 1,364 & \\
\hline \multirow[t]{3}{*}{$\mathrm{C} 2$} & \multirow{3}{*}{$\begin{array}{c}\text { ninguna } \\
102 \\
3 \text { o más }\end{array}$} & 7,25 & 0,622 & & 5 & 1,128 & \\
\hline & & 6,92 & 0,996 & & 5,42 & 1,084 & \\
\hline & & 6,59 & 1,278 & & 5,12 & 1,219 & \\
\hline \multirow[t]{3}{*}{$\mathrm{C} 3$} & \multirow{3}{*}{$\begin{array}{c}\text { ninguna } \\
1 \text { o } 2 \\
3 \text { o más }\end{array}$} & 7,67 & 0,651 & & 4,83 & 1,115 & \\
\hline & & 7,42 & 0,793 & & 4,92 & 1,165 & \\
\hline & & 6,88 & 1,317 & & 5,47 & 1,007 & \\
\hline \multirow[t]{3}{*}{ IC4 } & \multirow{3}{*}{$\begin{array}{c}\text { ninguna } \\
1 \text { o } 2 \\
3 \text { o más }\end{array}$} & 6,25 & 1,055 & & 4,08 & 2,021 & \\
\hline & & 6,17 & 0,937 & & 4,67 & 1,923 & \\
\hline & & 6,24 & 1,437 & & 4,35 & 0,931 & \\
\hline \multirow[t]{3}{*}{$\mathrm{C5}$} & \multirow{3}{*}{$\begin{array}{c}\text { ninguna } \\
1 \text { o } 2 \\
3 \text { o más }\end{array}$} & 7,25 & 0,866 & & 5,92 & 0,996 & \\
\hline & & 6,92 & 1,165 & & 5,33 & 1,231 & \\
\hline & & 6,53 & 1,068 & & 5 & 1,458 & \\
\hline \multirow[t]{3}{*}{ C6 } & \multirow{3}{*}{$\begin{array}{c}\text { ninguna } \\
1 \text { o } 2 \\
3 \text { o más }\end{array}$} & 7,33 & 0,651 & * & 4,58 & 1,676 & \\
\hline & & 7 & 0,953 & & 5,58 & 1,379 & \\
\hline & & 6,35 & 1,115 & * & 4,59 & 1,417 & \\
\hline \multirow[t]{3}{*}{$\mathrm{C7}$} & \multirow{3}{*}{$\begin{array}{c}\text { ninguna } \\
1 \text { o } 2 \\
3 \text { o más }\end{array}$} & 6,83 & 1,697 & & 4,92 & 1,881 & \\
\hline & & 7 & 1,206 & & 5,5 & 1,883 & \\
\hline & & 6,76 & 1,091 & & 4,76 & 1,2 & \\
\hline \multirow[t]{3}{*}{ C8 } & \multirow{3}{*}{$\begin{array}{c}\text { ninguna } \\
1 \text { o } 2 \\
3 \text { o más }\end{array}$} & 7 & 0,953 & & 4,83 & 1,642 & \\
\hline & & 6,58 & 1,24 & & 5,08 & 0,9 & \\
\hline & & 6,65 & 1,169 & & 5 & 1,732 & \\
\hline
\end{tabular}




\begin{tabular}{|c|c|c|c|c|c|}
\hline \multirow[t]{3}{*}{$\mathrm{C9}$} & \multirow{3}{*}{$\begin{array}{c}\text { ninguna } \\
1 \text { o } 2 \\
3 \text { o más }\end{array}$} & 6,5 & 1,567 & 5,25 & 1,545 \\
\hline & & 7,33 & 0,985 & 5,83 & 1,337 \\
\hline & & 7 & 1,173 & 4,94 & 1,519 \\
\hline \multirow[t]{3}{*}{ C10 } & \multirow{3}{*}{$\begin{array}{c}\text { ninguna } \\
1 \text { o } 2 \\
3 \text { o más }\end{array}$} & 7,25 & 1,138 & 4,67 & 1,969 \\
\hline & & 7,42 & 1,165 & 5,33 & 1,231 \\
\hline & & 6,59 & 1,77 & 4,41 & 1,543 \\
\hline \multirow[t]{3}{*}{ C11 } & \multirow{3}{*}{$\begin{array}{c}\text { ninguna } \\
1 \text { o } 2 \\
3 \text { o más }\end{array}$} & 6,67 & 1,073 & 5,08 & 1,505 \\
\hline & & 6,58 & 1,165 & 5,5 & 1,732 \\
\hline & & 7,06 & 1,029 & 5,29 & 1,448 \\
\hline \multirow[t]{3}{*}{ C12 } & \multirow{3}{*}{$\begin{array}{c}\text { ninguna } \\
1 \text { o } 2 \\
3 \text { o más }\end{array}$} & 6,42 & 1,165 & 5,83 & 1,337 \\
\hline & & 7,25 & 1,138 & 7 & 1,414 \\
\hline & & 6,94 & 0,827 & 6,41 & 1,278 \\
\hline \multirow[t]{3}{*}{ C13 } & \multirow{3}{*}{$\begin{array}{c}\text { ninguna } \\
1 \text { o } 2 \\
3 \text { o más }\end{array}$} & 5,92 & 1,73 & 5,83 & 1,403 \\
\hline & & 6,33 & 1,497 & 6,25 & 1,138 \\
\hline & & 6,65 & 0,862 & 5,53 & 1,419 \\
\hline \multirow[t]{3}{*}{ C14 } & \multirow{3}{*}{$\begin{array}{c}\text { ninguna } \\
1 \text { o } 2 \\
3 \text { o más }\end{array}$} & 6,33 & 1,155 & 4,58 & 1,24 \\
\hline & & 6,83 & 1,193 & 5,33 & 1,371 \\
\hline & & 6,06 & 1,144 & 4,65 & 1,367 \\
\hline \multirow[t]{3}{*}{ C15 } & \multirow{3}{*}{$\begin{array}{c}\text { ninguna } \\
1 \text { o } 2 \\
3 \text { o más }\end{array}$} & 6,75 & 1,215 & 5,25 & 1,658 \\
\hline & & 6,67 & 1,497 & 5,17 & 1,467 \\
\hline & & 6,47 & 1,125 & 4,88 & 1,536 \\
\hline \multirow[t]{3}{*}{ C16 } & \multirow{3}{*}{$\begin{array}{c}\text { ninguna } \\
1 \text { o } 2 \\
3 \text { o más }\end{array}$} & 7,75 & 0,452 & 5,17 & 1,642 \\
\hline & & 7,33 & 0,778 & 6,33 & 1,303 \\
\hline & & 7,24 & 1,091 & 5,35 & 1,222 \\
\hline \multirow[t]{3}{*}{ C17 } & \multirow{3}{*}{$\begin{array}{c}\text { ninguna } \\
1 \text { o } 2 \\
3 \text { o más }\end{array}$} & 7 & 1,279 & 4,83 & 1,467 \\
\hline & & 6,67 & 1,155 & 5,42 & 1,084 \\
\hline & & 6,24 & 1,522 & 4,71 & 1,16 \\
\hline \multirow[t]{3}{*}{ C18 } & \multirow{3}{*}{$\begin{array}{c}\text { ninguna } \\
1 \text { o } 2 \\
3 \text { o más }\end{array}$} & 6,92 & 0,793 & 4,75 & 1,545 \\
\hline & & 6,92 & 0,793 & 5,17 & 1,115 \\
\hline & & 6,65 & 1,115 & 4,88 & 1,616 \\
\hline \multirow[t]{3}{*}{ C19 } & \multirow{3}{*}{$\begin{array}{c}\text { ninguna } \\
1 \text { o } 2 \\
3 \text { o más }\end{array}$} & 7,42 & 0,9 & 4,5 & 2,067 \\
\hline & & 7,5 & 0,798 & 5,42 & 1,311 \\
\hline & & 6,88 & 1,111 & 4,82 & 1,629 \\
\hline \multirow[t]{3}{*}{ C20 } & \multirow{3}{*}{$\begin{array}{c}\text { ninguna } \\
1 \circ 2 \\
3 \text { o más }\end{array}$} & 7,33 & 1,723 & 3,58 & 2,503 \\
\hline & & 7,5 & 0,674 & 3 & 2,174 \\
\hline & & 7,24 & 0,97 & 3,47 & 2,154 \\
\hline
\end{tabular}

*Nivel de significación inferior al 0,05 


\section{4.- $\quad$ CONCLUSIONES}

Según los resultados obtenidos, estamos en disposición de afirmar que los alumnos creen que el nivel adquirido en todas las competencias es menor que la importancia que les conceden para su futuro desarrollo profesional. El Grado en Relaciones Laborales y Recursos Humanos ofrece dentro de sus itinerarios profesionales salidas eminentemente prácticas, por lo cual los estudiantes le conceden la máxima importancia precisamente a la competencia de aplicar los conocimientos a la práctica profesional. Detallando aún más, existe una diferencia estadísticamente significativa, que nos dice que son las mujeres las que le dan una mayor importancia. Igualmente piensan que ésta es una de las competencias donde poseen un mayor nivel de adquisición, pero a pesar de ello la diferencia entre ambas variables es de casi dos puntos, lo que denota aún cierto desajuste. Es decir, los estudiantes consideran que sería importante prestar mayor atención a la competencia "aplicar los conocimientos a la práctica”.

La mayor brecha se produce en la capacidad de comunicación en una segunda lengua, donde la diferencia de medias es de casi cuatro puntos. Resulta evidente que una de las mayores carencias no sólo en nuestro sistema educativo sino en nuestra sociedad en general se ve claramente plasmada en estos resultados.

Dado el carácter eminentemente multidisciplinar de estos estudios, que van a capacitar al estudiante para desarrollar diferentes tareas profesionales dentro del mercado de trabajo, resulta contradictorio que los alumnos perciban que la competencia C13 (trabajo en equipo de carácter multidisciplinar), tenga una menor importancia con respecto a otras (concretamente la cuarta con menor puntuación), y sin embargo consideren que poseen un buen nivel de adquisición, siendo una de las que evidencia un menor desajuste y donde no existe una diferencia estadísticamente significativa. Esto demostraría la implicación del profesorado en intentar conectar su disciplina con las restantes que ofrece esta titulación, y por tanto en formar profesionales con una visión polivalente del entorno laboral, pero quizás haya que transmitir la importancia de dicha competencia en sus estudios.

Los alumnos demandan una mayor capacitación en habilidades para la búsqueda activa de empleo, como signo de su preocupación de cara a su futuro una vez que finalicen sus estudios. Por tanto, es una competencia genérica en la cual la universidad tendría que prestar una mayor atención. Se da la circunstancia de que esta preocupación aumenta en alumnos de mayor edad, ya que existen diferencias significativas entre los tramos de edad de 22 a 24 años, y de 25 a 28. Igualmente los alumnos que proceden de bachillerato, consideran que poseen un mayor nivel en esta competencia que los alumnos que provienen de grados superiores de formación profesional.

Entre otros datos dignos de mención, podemos destacar la adquisición competencial de la aplicación informática relativa al ámbito de estudio (C6), donde el 
desfase se acerca a los dos puntos, es decir, los alumnos consideran que deberían tener un mayor nivel en una competencia fundamental y vital en un entorno laboral, donde se exige cada vez más el dominio digital relacionado con el trabajo. Existen diferencias estadísticamente significativas, según la situación de los encuestados en el mercado de trabajo, concretamente entre los alumnos que buscan empleo, que les dan una mayor importancia que los que trabajan. Igualmente, aquellos alumnos con más de tres asignaturas pendientes, le otorgan una menor importancia que aquellos alumnos que no tienen pendiente ninguna. También existen diferencias entre importancia y nivel en otra competencia estrechamente relacionada con la anterior, como es la utilización de las TICs para aprender, comunicarse y compartir conocimientos, existiendo diferencias estadísticamente significativas por sexos en la importancia otorgada, siendo las mujeres las que más la valoran. Hablamos de dos competencias fundamentales para competir con éxito en el mercado laboral y a las que habría que prestarle una mayor atención dentro de los procesos de enseñanza aprendizaje. Por último, destacan la importancia de saber transmitir sus ideas en público, sin embargo esta demanda parece no encontrar correspondencia con el nivel adquirido en ésta competencia, siendo también una de las que presenta mayor diferencia.

\section{5.- $\quad$ LIMITACIONES Y PROPUESTAS}

Los resultados de esta investigación son específicos de la titulación y curso analizado, con lo cual no podemos extrapolar los datos al resto de titulaciones superiores, ya que para ello habría que realizar estudios de mayor complejidad y calado. Sin embargo, los trabajos referenciados nos indican diferentes puntos en común. Sin duda alguna el más importante, es la diferencia existente entre la importancia y el grado de adquisición de las competencias. Al valorar en mayor medida la primera variable (importancia de la competencia), se evidencian carencias significativas en desarrollo de las competencias.

Centrándonos en la muestra analizada, podemos sugerir algunas propuestas de mejora:

Habría que cuestionar si conocen realmente los alumnos la importancia de la adquisición de las competencias, de cara a su futuro desarrollo profesional. Es fundamental que no se conviertan en un mero documento formal, sino que se haga participe al alumno de la trascendencia en su proceso educativo. Su implicación favorecería una adecuada formación en competencias.

Una vez conocidos los desajustes entre lo que los alumnos esperan y el grado de adquisición de las competencias analizadas, habría que intervenir desde un punto de vista docente, y adoptar medidas para reducir esas diferencias. Desarrollar acciones 
que permitan llegar a ese saber hacer, que junto a los conocimientos, aumentarán la empleabilidad de los estudiantes tras la finalización de sus estudios.

Por último, podemos plantearnos la siguiente cuestión: ¿Existe una evaluación real de las competencias? Si no es así, será muy difícil proponer acciones de mejora, ya que careceríamos del feedback que nos permita identificar las carencias existentes. La empresa evaluará la eficiencia de los titulados universitarios a la hora de cubrir un puesto de trabajo, sus conocimientos, destrezas y actitudes. Seria por tanto deseable que toda esa formación en su conjunto sea evaluada anteriormente, y de forma conveniente por la institución académica y por los docentes en particular.

La formación en competencias se puede hacer más accesible, si el alumno tiene la posibilidad de evaluarse y enriquecerse participando en actividades profesionales paralelas a sus estudios (Delors, 1996).

\section{6.- REFERENCIAS BIBLIOGRÁFICAS}

AA.VV. (2005). Libro blanco: Título de Grado en Ciencias Laborales y Recursos Humanos. ANECA.

ALONSO-MARTÍN P. (2010). La valoración de la importancia de las competencias transversales. Comparación de su percepción al inicio al final del curso en alumnos de psicología. Revista de investigación educativa 28(1), p 119-140.

Consejo Europeo de Lisboa. 23 y 24 de marzo 2000 Conclusiones de la Presidencia (http://www.europarl.europa.eu/summits/lis1.es.htm).

Comité de gestión de Tuning (2006). Una introducción a Tuning educational Structure in Europe. La contribución de las universidades al proceso de Bolonia. Education and cultura. Sócrates-Tempus. Pag.16-17.

COROMINAS ROVIRA, E. (2011). Competencias genéricas en la formación universitaria. Revista de educación no 325, p.299-321, Madrid.

DE MiGUEL DíAZ, M. (Dir.) (2006). Modalidades de enseñanza centradas en el desarrollo de competencias: orientaciones para promover el cambio metodológico en el Espacio Europeo de Educación Superior. Ministerio de Educación y Ciencia, Universidad de Oviedo, Oviedo.

ECHEVERRÍA, B. (2001): Configuración actual de la profesionalidad. Letras de Deusto, 31,35-55.

GONZALEZ, J., WAGENAAR., R; BENEITONE, P. (2004). Tuning-América Latina: un proyecto de las universidades. Revista Iberoamericana de Educación $n^{\circ} 35$, p.151-164. 
GONZÁLEZ, J.; WAGENAAR, R. (2006). Tuning educational structures in Europe. Informe Final, Proyecto Piloto - Fase 2. La contribución de las universidades al proceso de Bolonia. Universidad de Deusto, Bilbao. Pags 79 a 81.

Informe a la UNESCO de la comisión internacional sobre educación para el siglo XXI, presidida por Jaques Delors (1996).

LE BOTERF, G. (2001): Ingeniería de las competencias. Barcelona.Gedisa.

LUQUE PULGAR, E (2009). Encuesta piloto sobre competencias genéricas a egresados de la UNED. Instituto Universitario de Educación a Distancia (IUED)

MARTÍNEZ DE IBARRETA ZORITA, C. (2010.) Evaluación del grado de ajuste entre el perfil competencial demandado por las empresas y el obtenido por los estudiantes de ADE. Investigaciones de Economía de la Educación no 5, p.245-265.

RAMÍREZ MORENO, J.M, VELÁZQUEZ DORTA, A. (2010). Valoración de las competencias para el empleo en los titulados universitarios. I Congreso internacional de formación virtual del profesorado. La formación del profesorado en el siglo XXI: Propuestas ante los cambios económicos, sociales y culturales.

RODRIGUEZ ESTEBAN, A., VIEIRA ALLER, M.J (2009). La formación en competencias en la universidad: un estudio empírico sobre su tipología. Revista de Investigación Educativa, $n^{\circ} 27, n^{\circ} 1$, p. 27-47. 
